\title{
Portals and Pokémon: Geolocation Augmented-Reality Games for Physical Activity, Social Health and Community Awareness
}

\author{
Nicole Aydt Klein ${ }^{1 *}$, Megan L. Kaiser ${ }^{2}$ \\ ${ }^{1}$ Associate Professor, Department of Public Health Applied Health, Southern Illinois University, Edwardsville Edwardsville, IL 62025-1126, USA \\ ${ }^{2}$ Undergraduate Research Assistant, Department of Public Health Applied Health, Southern Illinois University Edwardsville, USA
}

\begin{abstract}
Article Details
Article Type: Research Article

Received date: $24^{\text {th }}$ July, 2017

Accepted date: $10^{\text {th }}$ October, 2017

Published date: $18^{\text {th }}$ November, 2017

"Corresponding Author: Department of Public Health Applied Health, Southern Illinois University, Edwardsville Edwardsville, IL 62025-1126, USA. E-mail: nklein@siue.edu

Citation: Klein NA, Kaiser ML (2017) Portals and Pokémon: Geolocation Augmented-Reality Games for Physical Activity, Social Health and Community Awareness. J Pub Health Issue Pract 1: 103. https://doi.org/10.33790/jphip1100103.

Copyright: (C2017, This is an open-access article distributed under the terms of the Creative Commons Attribution License 4.0, which permits unrestricted use, distribution, and reproduction in any medium, provided the original author and source are credited.
\end{abstract}

\begin{abstract}
Background: The newest generation of active games are locationspecific, augmented-reality (AR) apps including Niantic Lab's Ingress and Pokémon Go. Little is known about their effects on physical activity or the potential for social support and community awareness.
\end{abstract}

Purpose: This study qualitatively explores physical activity, social interaction, and community awareness for players of a geolocation augmented-reality game.

Methods: Twenty U.S. college students ages 18 to 21 learned the geo AR mobile game app, Ingress. Interviews about their experiences were recorded, transcribed and analyzed for themes using a phenomenological approach.

Results: Frequent players were predominantly female and three of the seven were overweight or obese. Participants who already exercised felt the game did not increase their physical activity. Half of the participants mentioned adding a small amount of activity with a few being much more active. Only three reported any effect on their social health, but almost all mentioned increasing their community knowledge.

Discussion: Geo AR games are promising to encourage activity for some who might otherwise be inactive. Translation to Public Health Practice: Mobile app games are a free, fun, and readily available tool for improving the health of college populations who may not be drawn to traditional programming.

Keywords: Physical Activity, College Student Health, Technology Introduction

OnlyoneinfiveAmericans reach the recommendedamount of physical activity (PA) needed to decrease the risk of heart disease, stroke, Type 2 diabetes, some cancers and depression [1]. Healthy People 2020, which sets the public health objectives and related federal funding priorities for the US every ten years, lists several targets spe- cific to physical activity. Objective PA-1 seeks to "Reduce the proportion of adults who engage in no leisure-time leisure-time physical activity [2]" which targets the approximately $30 \%$ of the population who are not physically active at all outside of work. In addition, the US federal government would like to see more Americans increase trips made by walking and bicycling. Important factors that are positively associated with PA are enjoyment of the activity, pleasant/ interesting scenery and social support [2]. Recent development of mobile games using GPS, such as Ingress, the geolocation augmentedreality mobile (cell phone/tablet) game released by Google's Niantic Labs, provide all three factors and other health enhancing benefits yet to be documented.

\section{Ingress Game Description}

Ingress is a free game application (app) available on Android and iOS devices that superimposes the virtual world of the game with a user's physical surroundings on a map (geolocation) viewed on a mobile device an experience known as augmented reality. It was developed by Google's Niantic Labs in 2012 and is played worldwide [3]. While Niantic Labs has not released the number of Ingress players, the social networking Google+ Ingress community has over 4.6 million followers as of January 2017 [4]. The game screen is an overlay that shows the player's current location using a mobile device's GPS and Google Maps. This overlay shows realworld locations, usually monuments, statues, art or historic sites that have been marked as "portals" in the game. Unlike prior mobile games such as Candy Crush, Angry Birds and Clash of Clans, these portals must be physically visited by players.

In order to interact with a portal, a player must move to within 40 meters of it. Once within range, a player can "hack" the portal. Hacking a portal causes it to give a player items to use in the game. Once hacked, a portal must cool down for 5 minutes before the same player can hack it again. This encourages players who are gathering items to physically move from portal to portal.

While it can be played individually, the game has a strong social dimension. When a player first starts playing Ingress, he/she must align with one of two teams, or factions: the Enlightened (green) or the Resistance (blue). Once a portal is owned by a faction, it can be "linked" to other portals controlled by players in the same faction, creating a "field". In order to link portals and create fields, players usually have to move repeatedly between portals (physical activity) and communicate and collaborate with multiple players in one's own faction, enhancing the social aspect of the play.

While it may be possible to move between game portals using a 
motorized vehicle (car, motorcycle, scooter, Segway), it is often impossible or at least disadvantageous. Portals are often clustered in groups in areas with above-average numbers of monuments, statues, and historic buildings like parks, college campuses, and historic downtown districts. These portal clusters are best visited on foot, bicycle or skateboard, encouraging physical activity in an individual who may be typically sedentary. The game itself will not function if a player is moving at a high rate of speed - for example in a vehicle in fast-moving traffic.

Initial observation of major cities' Google+ Ingress groups reveals thriving communities. Google's Niantic Labs launched the second season of Ingress Obsessed, an online video series with a two-part episode covering an attempt by the "Resistance" faction to capture the entire city of St. Louis, Missouri [5]. The seven-minute episode highlights the sense of excitement and community inspired by being part of an augmented-reality massively multiplayer online roleplaying game (MMORPG). Clips of players' physical activity and the young organizer's story of how being part of the game has helped him overcome depression and an eating disorder figure prominently. The game play and usage of Ingress challenges the stereotype of gaming as a sedentary activity that could be an option for health education programming.

Very little is known about physical activity as it relates to mobile games. Even less is known about the social support and community aspects of these games. Free mobile app games such as Ingress and Pokémon Go are an opportunity for health education specialists to incorporate a fun, readily available tool for improving the health of populations.

\section{Purpose}

While informal interactions with members of the Ingress community indicate that involvement with the game increases both the physical and social health of the players, there is little empirical research about these benefits. What is known about the health effects on the players is currently anecdotal only. Therefore, this study explores how this new technology can influence the health of its users. Specifically, this study examines players' experiences, particularly physical and social health effects, after being introduced to the geolocation augmentedreality game, Ingress.

\section{Materials and Methods}

Using structured one-on-one interviews, participants who had never played Ingress were asked nine open ended ended questions about their experience with the game after being introduced to it at least 2 weeks prior. Data collection and analysis procedures were designed using phenomenological methods to better understand the participants' experiences to inform future health education/ promotion programming [6]. While additional mea- surements of participants' physical activity and psychosocial health were collected to be reported elsewhere, the goal of this study was to qualitatively explore and represent what happens after learning a new game and how that may affect a participant's social and physical health. Data collection began following approval of the study protocol from the university's Institutional Review Board in March 2016.

\section{Sample}

College students between the ages of 18 and 21 at a small midwestern public university were recruited via social media (e.g. Twitter, Instagram, Facebook). Recruitment efforts used universityspecific groups, pages and tags specifically targeting 1st and 2nd year students--for example, the university Twitter feed for the Class of 2019. Potential participants were directed to a link to the study's screening questionnaire via Qualtrics to determine eligibility for enrolling in the study. Criteria for selection included: (1) being between the ages of 18 and 21; (2) owning a smart phone with a data plan; and (3) having never played Ingress, described as a mobile augmented-reality game app. Of the 247 who participated in the screening questionnaire, twenty-one (21) who met the criteria were selected using a stratified purposeful sample to provide roughly equal representation of self-identified females and males.

This university was particularly suited to the goals of the study. Located in the metropolis of a major Mid- western U.S. city, participants had access to a large campus acreage with many outdoor art installations and sig- nificant buildings that serve as "portals" for active game play. Many more portals could be found in the city 20 minutes away, where Ingress communities arrange regular team "maneuvers". Over $45 \%$ of the approximately 10,000 undergraduates at the university were freshmen- or sophomore-level, assuring a participant pool within the ages of the study parameters.

\section{Procedures}

Selected participants completed a written questionnaire that included self-reported height and weight, psycho- metric measures and demographic information and signed an informed consent. Each participant attended one of several small group trainings lead by a consulting Computer Science faculty member and experienced user of the app. Beginning the 30-minute session, participants viewed a two-minute introductory video from Niantic Labs, creator of the Ingress app, that provided the fictional premise of the game [7]. Care was taken to ensure that the participants understood that the game is played in RTS - real time and space, meaning that it requires moving physically close to the target, using the phone's GPS. Assisted by an expert consultant, a research assistant and the researcher, participants downloaded the game app, selected their team faction and user name and began playing Ingress. As new players of the game, participants were shown the basics of game play, including how to locate and "hack" portals (physical landmarks) for points, attack enemy portals, collect and leave "portal keys" and post/ read on the communication link to other players. To conclude the training, participants demonstrated being able to hack a portal. After successful completion of the training, participants received a $\$ 10$ Amazon gift card via email. Participants were deliberately not given minimum requirements for using the app to allow insight into natural (non-study) playing behaviors.

Two to three weeks after learning the game, participants who completed the training and user period were contacted via email to come to the researcher's office for an interview about their experience with the game and its effect on their physical and social health. Upon entering the office, participants were greeted, seated, and reminded of the confidentiality of their participation. A short introduction provided the purpose of the study and let the participant know the interviewer would be taking notes and audio recording. Their right to pass on questions or end at any time and was made clear and participants were informed that the study and researcher was in no way involved with or invested in Google or Niantic Labs, the creators of the Ingress app. After answering any questions the participant had, the researcher then started the digital audio recording device, stated the date and participant number and began with the structured questions, taking notes on the interview protocol.

The interview questions were deliberately broad, as recommended for conducting phenomenological research, focusing on the participant's experiences with the mobile game app, including amount of play, supports and barriers to play and the effect the app had on their physical and social health. The questions were pilot tested with two undergraduate students and one experienced Ingress player. Feedback from the pilot testing lead to two additional questionsone about knowledge of the community due to playing Ingress and one about inviting others to play. See Table 1 that lists the specific interview questions. 


\begin{tabular}{|l|}
\hline Question \\
\hline 1. How often did you find yourself playing Ingress since learning it? \\
\hline 2. What helped support you playing? \\
\hline 3. What barriers kept you from playing? \\
\hline 4. What effect did playing have on your physical activity? \\
\hline 5. How did playing Ingress affect your social life? \\
\hline $\begin{array}{l}\text { 6. What effect did playing Ingress have on your knowledge of the community? For example, [university] } \\
\text { campus or other places you played? }\end{array}$ \\
\hline 7. Did you invite anyone else to play Ingress? \\
\hline $\begin{array}{l}\text { 8. What did you learn while playing Ingress? What would you like us to know about Ingress and its effect } \\
\text { on those who play it? }\end{array}$ \\
\hline 9. Do you plan to continue to play Ingress? \\
\hline
\end{tabular}

Table I. Primary Structured Interview Questions for Participants

Interviews lasted between three and twenty-six minutes and participants were provided a \$20 Amazon gift card for participation in the survey. Some participants played the game during the training, but did not play again after the first day or two and were likely to have very little to share beyond the barriers to playing. These interviews typically lasted between three to five minutes.

\section{Analysis}

The analyses focused on examining the descriptions of participants' engagement and self-described effects playing Ingress had on their social and physical health. All interviews were transcribed by the researcher and two research assistants, then checked for accuracy by randomly comparing the typed electronic document against the audio recordings. Phenomenological methodology was used to develop a coding scheme from the transcripts based on the broader domains from the interview (physical activity and social health) [6]. The interview transcripts were printed, then read through several times, while the researcher made notes along the margins. These memos consisted of ideas, reactions and questions related to the participants' answers. During this process all transcripts were independently analyzed by the primary investigator and a research assistant to sort the responses into categories. After reviewing and discussing the inital categories, similar concepts were collapsed into themes. Using these themes, the researcher and assistant made a preliminary count throughout all 20 interviews to deter- mine how often themes were mentioned in the interviews. Representative quotes were then chosen to illustrate the themes.

In addition, participants were labeled as either infrequent (played less than once per week), somewhat frequent (played weekly but not daily) or frequent (daily) players based on their responses to the question "How often did you find yourself playing Ingress since learning it several weeks ago?". Based on their responses to the initial questionnaire given prior to the Ingress training, sex, age and BMI were noted on each participants' transcript and are provided as context for the representative quotes reported in the results.

\section{Results}

One participant reported not having time to complete the study and withdrew resulting in twenty participant interviewsthroughout the month of April 2016. The interview participants averaged 18.9 years of age, were predominantly White $(60 \%)$ and female $(55 \%)$. Most were first-year students $(60 \%)$, enrolled full-time $(75 \%)$ and living in a university residence hall (55\%). From calculations of body mass index (BMI) from participants' self-reported height and weight, $45 \%$ were overweight or obese (BMI above $25 \mathrm{~kg} / \mathrm{m}^{2}$ ), $50 \%$ were normal or healthy weight (BMI 18.5-24.9 $\mathrm{kg} / \mathrm{m}^{2}$ ) and one participant (5\%) was underweight (BMI below $18.5 \mathrm{~kg} / \mathrm{m}^{2}$ ), according to US standards [8]. All participants owned a cell phone with a data plan and downloaded the Ingress game app when directed at the beginning of the study. Table 2 summarizes the full demographic data of the sample.

\begin{tabular}{|c|c|c|}
\hline Demographic & Number $(n=20)$ & Percentage $\%$ \\
\hline \multicolumn{3}{|l|}{ Sex } \\
\hline Female & 11 & 55 \\
\hline Male & 9 & 45 \\
\hline \multicolumn{3}{|l|}{ Race and ethnicity } \\
\hline White, non-Hispanic & 12 & 60 \\
\hline Asian, Pacific Islander & 3 & 15 \\
\hline $\begin{array}{l}\text { Black/African- } \\
\text { American }\end{array}$ & 2 & 10 \\
\hline Multiracial, biracial & 2 & 10 \\
\hline Hispanic/Latino(a) & 1 & 5 \\
\hline \multicolumn{3}{|l|}{ Age } \\
\hline 18 & 7 & 35 \\
\hline 19 & 10 & 50 \\
\hline 20 & 2 & 10 \\
\hline 21 & 1 & 5 \\
\hline \multicolumn{3}{|c|}{ BMI (self-reported weight and height) } \\
\hline $\begin{array}{l}\text { Underweight (BMI } \\
\text { below 18.5) }\end{array}$ & 1 & 5 \\
\hline $\begin{array}{l}\text { Normal (BMI 18.5- } \\
24.9 \text { ) }\end{array}$ & 10 & 50 \\
\hline $\begin{array}{l}\text { Overweight (BMI 25- } \\
\text { 29.9) }\end{array}$ & 5 & 25 \\
\hline $\begin{array}{l}\text { Obese (BMI above } \\
29.9 \text { ) }\end{array}$ & 4 & 20 \\
\hline \multicolumn{3}{|c|}{ Table 2. Cont......... } \\
\hline
\end{tabular}




\begin{tabular}{|c|c|c|}
\hline \multicolumn{3}{|l|}{ Enrollment status } \\
\hline Full-time & 15 & 75 \\
\hline Part-time & 5 & 25 \\
\hline \multicolumn{3}{|l|}{ Undergraduate year } \\
\hline 1 st & 12 & 60 \\
\hline 2 nd & 6 & 30 \\
\hline $3 \mathrm{rd}$ & 2 & 10 \\
\hline \multicolumn{3}{|l|}{ Residence } \\
\hline Residence hall on campus & 11 & 55 \\
\hline Off-campus & 6 & 30 \\
\hline With parents/family & 2 & 10 \\
\hline Other on-campus housing & 1 & 5 \\
\hline
\end{tabular}

Table 2. Participant Characteristics

In the interviews conducted two to three weeks after downloading and learning Ingress, how much partic- ipants used the game varied. They were given no minimum requirements about how much time to play in order to explore the natural progression of gameplay that would be likely in a non study population and to see what barriers kept them from playing. Eight were infrequent players - most reporting that if they played, it was when they were first introduced to the game, but play did not continue much beyond that. "The first two days I played a lot then I like, just completely forgot about it" (20 year old male, $18.9 \mathrm{BMI} \mathrm{kg} / \mathrm{m}^{2}$ ). Five were somewhat fre- quent players who would play daily, but would not go out of their way to move closer to portals. "I played it mostly when I was walking to classes, so it was the easiest for me to hit as many different points..." (19 year old female, 19.5 BMI kg/ $\mathrm{m}^{2}$ ). Seven were frequent players who played regularly and specifically made efforts to locate portals. "I thought at first, I'd play it for the study, but then after having played and got into it, I actually found myself enjoying it and found myself going out of my way not even around campus but also around [city], trying to capture the different points" (20 year old male, 40.2 BMI $\mathrm{kg} / \mathrm{m}^{2}$ ).

The frequent players were predominantly female $(5: 2$ female to male). Of the seven frequent players, two were obese, and one was overweight, as classified by their BMIs. Only one of the somewhat frequent players was overweight and none were obese. Five of the eight infrequent players had BMIs over $25 \mathrm{~kg} / \mathrm{m} 2$.

\section{Physical Activity}

Half of the participants reported that there was no change in their physical activity due to their involvement with the game. When asked, one participant said "I don't think it affected it at all" (18 year old female, 20.4 BMI kg/m²). Six of the ten who said the game had no effect on their physical activity reported that they were already regularly physically active. "I feel like it didn't really have much effect. I still went to the gym every day for two hours" (19 year old female, 26.0 BMI kg/m²). Another participant who was an infrequent player when asked how the game affected her physical activity responded that "I feel like it didn't, unless I didn't get into it enough because I was already perfectly or pretty physically active. I get up every morning and work out..." (18 year old female, 22.3 BMI kg/ $\left.\mathrm{m}^{2}\right)$.

Most commonly, those who reported an increase in physical activity mentioned that they would add a small amount of activity to their already established routes to be able to encounter targets. “... when I was out of class I would walk a little bit further to get that portal, J Pub Health Issue Pract

Volume 1.2017. 103 but not much" (19 year old female, 24.1 BMI kg/m²). Others reported much more activity. "It had me moving a lot more than I usually do because usually in between classes I just kind of sit around and do nothing so with Ingress I had something to do" (18 year old female, 26.9 BMI kg/m²). "[It] made me walk a lot more" (18 year old female, 19.2 BMI kg/m²). One participant related a story about eating lunch with his girlfriend at a park and it turning into a long walk due to the game. "You know, usu- ally we probably would have ate lunch, you know, talked a little, walked around. Whereas because of the game, I wanted to walk allll around the park claiming all these different territories. So a usual 15 minute walk turned into about a 45 minute, an hour walk" (20 year old male, 40.2 BMI kg/m2). Table 3 summarizes respondents' responses that both supported and hindered physical activity due to the game.

\begin{tabular}{|l|}
\hline Categories \\
\hline Physical Activity \\
\hline+ Played while walking to class \\
\hline+ Could add extra walking to already planned events \\
\hline+ Fun \\
\hline+ Liked competing \\
\hline -Already physically active/no need for more \\
\hline -Concerned about safety while playing \\
\hline -Playing did not increase PA \\
\hline Social Effect \\
\hline+ Recruited others to play \\
\hline+ Found others that were already playing \\
\hline+ Liked being part of a team \\
\hline+ Liked chatting on "comm link" \\
\hline -Unsuccessful at recruiting others \\
\hline -Friends would negatively judge for playing \\
\hline -Did not join "maneuvers" \\
\hline -Did not read and/or join "comm link" chat \\
\hline Community Awareness \\
\hline+ Increased awareness of art/structures in community \\
\hline+ Challenged to find new places \\
\hline+ Increase in spatial ability \\
\hline
\end{tabular}

Table 3. Response Categories and Themes of Participants' Experiences with Geolocation Augmented Reality Game, Ingress

\section{Social Effect}

Few participants reported any effect on their social health. Of the three who said it increased their social connections, two recruited others. "I got my roommates to play it... we usually eat lunch together so we would play it while we go eat lunch or after lunch. It was pretty fun to play with somebody else" (18 year old female, 19.2 BMI kg/ $\mathrm{m}^{2}$ ). Another participant talked to his fraternity president about setting up an Ingress event with a rival fraternity. One active player reported that his mother had played Ingress from its inception and once he started playing, he found that several of his current friends were players as well. "You'd start actively searching out other people who are doing it so then you could have that shared connection" (19 year old male, $24.4 \mathrm{BMI} \mathrm{kg} / \mathrm{m}^{2}$ ).

Not only did few participants report increasing their social connections, but several mentioned that they deliberately did not ISSN- 2581-7264 
play the game around others. Several participants mentioned not wanting to be absorbed on their phones while in the company of others. "If I was with someone, I was talking to them instead of engaged in my phone" (19 year old female, $21.1 \mathrm{BMI} \mathrm{kg} / \mathrm{m}^{2}$ ). When asked how it affected her social life, one participant said "Whenever I would be with other people, I'd be talking to them, but from time to time 'Oh, hey-yeah-there's a portal here so I'm going to go capture it, alright?"” (19 year old female, 26.0 BMI kg/m²).

The game automatically announces significant game action (e.g. capturing or losing a portal) within a geographic range of the player via rolling text script. There is an option that allows posting instant text message communication between players, either within their own faction-blue or green, or across teams. This is known as the "comm link", and was decidedly unpopular among the participants surveyed. While some looked at the comm link "I was scrolling through what people were saying and stuff and was like, okay. I didn't really use it because I was like-I don't really know what I'm doing" (19 year old female, 26.0 BMI kg/m²), only one participant used it to ask questions of other players, somewhat unsuccessfully. "Most of the time they answered back, but they're also new, so not all of them knew what they were doing either" (19 year old female, $22.3 \mathrm{BMI} \mathrm{kg} / \mathrm{m}^{2}$ ).

A few participants mentioned being actively uncomfortable with the comm links. "Those kind of weirded me out. A bunch of people asked me to come to certain places to get points and I was like, I don't know if that is a thing. It sounded like when they talked to you in school, like middle school and they're like 'Don't ever talk to anyone on the internet..."' (19 year old female, $27.3 \mathrm{BMI} \mathrm{kg} / \mathrm{m}^{2}$ ). Another who was greeted by another player on the comm link said "...I don't like doing anonymous chats. That kind of thing makes me feel a little uncomfortable, so I stayed away from that" (18 year old male, 19.9 BMI kg/m2). Although the sex of players isn't revealed, when asked about the comm links, one participant reported that "A lot of times it was just boys saying stupid things and I'm like 'I have nothing to contribute to this'. Like there's no point in me talking to these people" (19 year old female, 19.5 BMI $\mathrm{kg} / \mathrm{m}^{2}$ ). See Table 3 for the categories of responses related to the effect of playing the game on participants' social health.

\section{Community Awareness}

The most consistently mentioned effect of playing Ingress was one that was not anticipated by the original study questions--participants' knowledge of the community. Almost all participants reported learning more about the areas where they played. Many mentioned increased awareness of art on campus. "I found different portals around and I found art work and stuff like that which was pretty cool. And when I was at home, every time I went to places like restaurants or parks, there was just always something there" (19 year old female, $33.3 \mathrm{BMI} \mathrm{kg} / \mathrm{m} 2$ ). When asked about the effect of the game on her knowledge of the community, another participant said "Things you kind of take for granted I guess, like art... [I] just kind of would have walked past it, so I thought that was cool" (18 year old female, 22.3 BMI kg/m2). Another player mentioned finding a park near where he lives. "I live right by there and I probably would have never known that there was the place back there if I didn't see the portals and stuff' (19 year old male, $26.2 \mathrm{BMI} \mathrm{kg} / \mathrm{m} 2$ ). One participant discovered that there was a portal in the front yard of her family's home.

A few participants mentioned that playing strengthened their navigation skills. "It helped my GPS skills... like following directions of where it's telling me to go" (19 year old female, $21.1 \mathrm{BMI} \mathrm{kg} / \mathrm{m}^{2}$ ). One participant described how the game pushed him out of his usual walking routes on campus. "You're learning more about where you are, how things are related to each other - it helps with your spatial reasoning" (19 year old male, $24.4 \mathrm{BMI} \mathrm{kg} / \mathrm{m}^{2}$ ). Others reported deliberately exploring more due to the game. "One thing I've learned is to take in more [of] my surroundings...I'm driving around [and] I'll see a cemetery and a nice huge statue and I'm like, 'I bet that's one of the terminals I could capture"' (20 year old male, 40.2 BMI kg/ $\mathrm{m}^{2}$ ). Table 3 lists the categories of responses given when asked about the effect of playing on participants' knowledge of the community.

\section{Barriers to Use}

While reactions to the game were generally positive, there were several main barriers mentioned by participants - one device-related and the others game-related. Ingress uses GPS via Google Maps and is a heavy user of data and battery life. This was a concern to some of the participants who found themselves minimizing play or limiting their range to areas with wi-fi, such as the inner core of campus. While most of the participants reported being able to understand the basics of the game, for some the game play was difficult to grasp. One participant reported not being able to play the game after the training. "I just really didn't understand what the concept was. I knew you could hack the portal, but I didn't really know what I was doing when I did it...I couldn't figure out how to play it so it just wasn't fun for me" (18 year old male, $30.4 \mathrm{BMI} \mathrm{kg} / \mathrm{m}^{2}$ ). Other participants reported being unable to "hold" an area due to either not understanding how to do it, or not having achieved the level of mastery required to defend it.

Access to areas where there were portals was a necessity to play. A few participants, mainly those who lived in rural areas, reported few opportunities to play while off campus. "I am a commuter, so I usually don't spend that much time on campus and that's where all the portals that I know of are. Because around the area that I live, there's almost no portals whatsoever so it's a bit harder to play" (18 year old female, 26.9 BMI kg/ $\mathrm{m}^{2}$ ). Another participant when asked about continuing to play Ingress when he went home over the summer said, "I come from a really small town. There were no portals in my town so there's not really a way I could play it" (18 year old male, $30.4 \mathrm{BMI} \mathrm{kg} / \mathrm{m}^{2}$ ).

Many participants mentioned having limited time to play the game. "I get done with work really late and I go to school really early in the morning, so yeah, I don't really want to walk around outside at night (laughs)" (18 year old female, $20.4 \mathrm{BMI} \mathrm{kg} / \mathrm{m}^{2}$ ). A few mentioned the demands of finals week prohibiting them from playing. When asked about ease of playing, one participant responded "I feel like I would have gotten pretty far in it...I was very preoccupied and the past couple weeks I've just had tests all the time, so that kind of distracted me too" (19 year old female, 26.0 BMI kg/m²). See Table 4 for both barriers and facilitators to game play.

\begin{tabular}{|l|l|}
\hline Facilitators & Barriers \\
\hline Ease of having it on the phone & Time--too busy to play \\
\hline Plays other games on phone & $\begin{array}{l}\text { Cannot play if walking in a } \\
\text { hurry }\end{array}$ \\
\hline Easy to understand game & Cannot play while driving \\
\hline $\begin{array}{l}\text { Urge to play to move to next } \\
\text { level }\end{array}$ & $\begin{array}{l}\text { Remembering they had new } \\
\text { game too hard }\end{array}$ \\
\hline Discovering new places & Doesn't play phone games \\
\hline Can fit into existing activities & Bad weather \\
\hline Fun story & $\begin{array}{l}\text { No/few portals near home } \\
\text { Lost interest/boring/not fun } \\
\text { Phone issues (e.g. battery, } \\
\text { reception) } \\
\text { Gameplay issues (difficulty, } \\
\text { chat function) }\end{array}$ \\
\hline
\end{tabular}

Table 4: Participants' Self-Reported Facilitators and Barriers to Use of Geolocation Augmented Reality Game, Ingress 


\section{Discussion}

The findings from this qualitative study provide insight into players' physical activity, social health and community awareness when using one of the newer free game apps available for mobile devices. These geolocation augmented-reality games differ from exergamesgames whose main focus is to make exercise more enjoyable. Geo AR games have entertainment and competition at the forefront with physical activity as a secondary result. Ingress and Pokémon Go focus on the story and characters, the accomplishments for their team and gaining experience levels, all which require players' physical presence at game locations. In this, the po- tential exists to appeal to individuals who might not typically play traditional exergames such as Dance, Dance Revolution or Nintendo Wii games.

These results also suggest that the mindset of playing a game can encourage activity for some who might otherwise be inactive. Participants who already engaged in regular exercise were less likely to report that the game increased their physical activity. When examining the BMIs of players, overweight or obese participants tended to be either frequent Ingress players or infrequent-not moderate players, perhaps indicating that this is an appealing activity for some, but not all who may not be reached by traditional fitness programming. For some, physical activity can feel like a dreaded task, but when presented in a game format, it may be much more appealing. For those who increase their activity and begin to see benefits, there is the potential that experience could lead to engaging in other forms of exercise.

Moderate- and high-level players seemed to use the game in several ways. Most often, they would play if it fit into what they were already doing. Participants already traveling to classes, residence halls and dining services would simply expand or alter their routes somewhat to encounter portals to capture. Others who would typically spend time between classes hanging out at the student union or in the building hallways and classrooms reported walking outside instead to hack nearby portals. Those who played at higher levels did the same, but to a greater degree and added Ingress outings where the goal of their activity was to travel to locales where they could play.

It is tempting to assume that geo AR games appeal only to experienced "gamers", an identity more men than women claim, despite reports that women are as likely to report playing video games as men [9]. However, in this study, most of the frequent players were women and only one (male) identified as a gamer. Most of the other frequent players did not report heavy use of other games or a need to be familiar with gaming to play.

While geo AR games have the potential to reach sedentary populations, they do not necessarily appeal to all. Two participants had no interest at all in playing a game and did not play at all past the original training day. "I'm not a gamer or neither do I play a lot on the phone or something. I just use it for texting and checking my emails and stuff" (19 year old male, 26.6 BMI kg/m2). The other participant, who mentioned not enjoying exercise either, stated, "I personally don't like games. I think they are a waste of time ...I like concept of the game, to be honest it is interesting, but it's just not me, I think" (21 year old male, 30.0 BMI kg/m2). For those who feel similarly, games like Ingress and Pokémon Go will not likely be an avenue for regular physical activity.

The study's original hypothesis was that playing a game that many others play would have a positive effect on participants' social health. This was not supported. Unlike console (PSP, GameCube, Wii) and mobile games (Candy Crush, Angry Birds), a geo AR games require physical movement and proximity. A certain amount of socializing with other players while physically present at portals was expected. However, in this study, the opposite seemed to be true. For those who gather at a portal to play Ingress, it can be difficult to tell who is playing, and who is simply reading or using social media in a public space. Unlike Pokémon Go, which requires a visually distinctive finger motion, Ingress uses common tap and drag motions that can go undetected. While the opportunity for instant messaging is built into the game play through the comm link, in this sample, players were unlikely to use it and some were discomfited by it.

Geo AR games such as Ingress have a strong potential to increase awareness of community resources, culture and history. All those who played at least weekly mentioned finding out more about their surroundings. Many were surprised at the number of locations designated as portals, especially in large concentrations on the university's campus. Players are given the names of buildings, parks, monuments and art installations with brief descriptions. Given that portals in Ingress are also "Poke-stops" in Pokémon Go, this is likely to increase the number of players who are exposed to community information, potentially increasing knowledge and connection to the campus and surrounding areas.

This research is not without limitations. Being a qualitative study, it provided information on a small number of participants, limiting the ability to generalize the findings. The majority of the participants were white, which may not provide insight into diverse populations. Participants were not given requirements for a specific amount of time playing, which led to some participants playing very little. While this was intentional to simulate what those outside of a study might do, it did limit length and depth of the interviews. One focus of the study was participants' own perceptions of changes in their physical activity due to the game, whereas measuring activity with a pedometer would have yielded an objective measure. This is the next step for this research. Finally, participants self-reported their height and weight to provide data for BMI calculations. This can be subject to participant error and potential social desirability bias, although self-reports have been found to be accurate [10].

\section{Conclusion}

Healthy Campus 2020 seeks to increase the proportion of U.S. students who are at a healthy weight (NWS-8) [11], defined as a BMI of $18.5-24.9 \mathrm{~kg} / \mathrm{m} 2$. In part, to do so, students must be encouraged to decrease sedentary behavior. Geolocation augmented-reality games such as Ingress can be used as a free-to-play tool for health education programming. While not high intensity activity, it could contribute to players to "search, not sit" and "hack, not slack".

Programming possibilities for geo AR games abound. Fitness centers could help players prepare for day-long, large scale events, addressing a fitness plan for building endurance and proper hydration on the day of the event, much like marathon preparations. Universities can offer geo AR-themed walking tours for different levels of players lead by different campus resources. Some ideas could include a history tour, discovering art, best-views, gaming the local parks, day trips sponsored by campus recreation to portal/Pokestop-rich cities, walk-a-dog while you game, alumni events, potential student tours, gamer park clean-up day, Big Brother/Big Sister events and programming for student parents and their children. Health education programs can address how to stay safe while playing and provide giveaways that support activity such as water bottles, reflectors, and $\mathrm{t}$-shirts indicating team affiliation. Support from experienced players for those who are just beginning to play and advanced train- ing for players who would like to learn more could be conducted in a walking classroom environment.

At a minimum, for those who enjoy the competitive play aspect, health education specialists can organize team play events, encouraging teams to take over the other's portals. For those who appreciate cooperative play a mission to coordinate with others to complete fields may be appealing. For non-residential commuter students who often present programming challenges can be encouraged to stay on campus for Ingress events designed to help them connect with other students and the campus environment.

JPHIP, an open access journal ISSN- 2581-7264 
While there is little known about whether those who learn the game continue to play, initial responses to the game were promising. "I think it was really cool how it got people up and moving and the missions have you going all over the place to look for portals" (18 year old female, $26.9 \mathrm{BMI} \mathrm{kg} / \mathrm{m}^{2}$ ). Another participant summed his experience, saying "Especially in the age of technology where everyone is just so consumed with just looking at a screen, you forget that there is a whole world around you, you know? So I think that was definitely one of the big things I took from it, is just look around you. There is so much more than just sitting here just waiting for a class to start" (19 year old male, 24.4 BMI kg/m²).

As others have noted [12], there are exciting possibilities for future research, development and application. Geolocation augmentedreality games such as Ingress require little investment-free app, ubiquitous cell phones and campus wi-fi-for strong potential gains in college students' physical activity and community awareness.

\section{Participant Consent Statement}

Informed consent was obtained from all participants included in the study as approved by the university ethics review committee where the data were collected.

\section{References}

1. US Department of Health and Human Services (2008) Office of Disease Prevention and Health Promotion. Physical activity guidelines advisory committee report.

2. U.S. Department of Health and Human Services (2010) Healthy People 2020: Objectives for the Nation.

3. Goel V (2016) Ingress has the world as its game board. New York Times.

4. Google+ Ingress.

5. Ingress Obsessed. [Video]

6. Creswell JW (2013) Qualitative Inquiry \& Research Design: Choosing Among Five Approaches.

7. Niantic. [Video]. Ingress-It's time to move.

8. Centers for Disease Control and Prevention.

9. Pew Research Center (2015) Gaming and Gamers [Report].

10. Bowman RL DeLucia JL (1992) Accuracy of self-reported weight: A meta-analysis. Behavior Ther 23: 637-655.

11. American College Health Association (2020) Healthy Campus.

12. Baranowski T (2016) Pokémon Go, go, go, gone? Games for Health J 5: 293-294. 